\title{
Depth-of-Fissure Cerebellar Infarcts in Adults
}

W ith great interest, we read the article "Cerebellar Watershed Injury in Children." The authors described 23 children with focal signal abnormalities in the depth of cerebellar fissures and hypothesized watershed injury as their presumed mechanism, in opposition to "bottom-of-fissure" dysplasia. We have occasionally encountered similar cerebellar imaging findings in children, and we have also ascribed these to watershed ischemia instead of cortical dysplasia.

The authors described 4 reasons to hypothesize that the pathologic basis for the "depth-of-fissure" MR imaging sign is cerebellar watershed injury rather than a congenital malformation: 1) location at the deep borderzones, 2) association with supratentorial watershed infarcts, 3) restricted diffusion in the acute phase, and 4) frequent late foliar volume loss with fissural prominence. ${ }^{1}$

In this letter, we would like to further support this hypothesis by comparison with the MR imaging appearance of cerebellar infarcts observed in adults. In 2015, we published the 3D MR imaging patterns of cerebellar infarcts with respect to anatomic boundaries, including fissures, ${ }^{2}$ because we had renounced the traditional borderzone classification because of the high interindividual variability of perfusion territories and thus borderzones. ${ }^{3,4}$ In essence, in an anatomic MR imaging study of 138 cerebellar infarcts observed in 70 different patients, we found that the overwhelming majority of cerebellar infarcts involved the cortex and most often occurred in the apex of cerebellar fissures; $47 \%$ of cortical infarcts involved the apex of a large fissure, and $11 \%$, of a smaller fissure. ${ }^{2}$ In larger infarcts, the apexes of multiple adjacent fissures were seen to be involved, also in the same way as in children. ${ }^{2}$ Last and also analogous to the recent MR imaging findings in children, the cerebellar vermis was seen, in our study, to be spared in $>90 \%$ of infarcts. $^{2}$

Although we used the term "apex of a fissure," this corresponds to the same typical imaging pattern of bottom-of-fissure or depthof-fissure infarct with involvement of the cortex and sparing of the subjacent white matter. In a postmortem 7T radiologic-pathologic correlation study, we confirmed the ischemic origin and cortical predilection of these lesions, typically with only microscopic changes in the subjacent white matter. ${ }^{5}$ Finally, in 2 more studies, we correlated these cortical infarcts with markers of cerebrovascular disease and vertebral artery stenosis and found that the same infarcts may demonstrate an atherothrombotic as well as a thromboembolic origin. ${ }^{6,7}$

http://dx.doi.org/10.3174/ajnr.A6626
In conclusion, the depth-of-fissure sign, which is best appreciated in the coronal or sagittal plane, is an easy MR imaging sign to diagnose cerebellar infarcts in all stages and applies to adults in addition to children. This interesting similarity between cerebellar infarcts observed in children with watershed injuries compared with adults with arterial thromboembolism may add evidence to an older hypothesis that hypoperfusion and thromboembolism are not mutually exclusive, but rather complementary and interrelated instead. ${ }^{8}$

\section{REFERENCES}

1. Wright JN, Shaw DW, Ishak G, et al. Cerebellar watershed injury in children. AJNR Am J Neuroradiol 2020;41:923-28 CrossRef Medline

2. De Cocker LJ, Geerlings MI, Hartkamp NS, et al; SMART study group. Cerebellar infarct patterns: the SMART-Medea study. Neuroimage Clin 2015;8:314-21 CrossRef Medline

3. Hartkamp NS, De Cocker LJ, Helle M, et al. In vivo visualization of the PICA perfusion territory with super-selective pseudo-continuous arterial spin labeling MRI. Neuroimage 2013;83:58-65 CrossRef Medline

4. De Cocker LJ, van Veluw SJ, Fowkes M, et al. Very small cerebellar infarcts: integration of recent insights into a functional topographic classification. Cerebrovasc Dis 2013;36:81-87 CrossRef Medline

5. De Cocker LJ, van Veluw SJ, Biessels GJ, et al. Ischaemic cavities in the cerebellum: an ex vivo 7-Tesla MRI study with pathological correlation. Cerebrovasc Dis 2014;38:17-23 CrossRef Medline

6. De Cocker LJ, Kloppenborg RP, Y, van der Graaf, et al; SMART Study Group. Cerebellar infarct cavities: correlation with risk factors and mri markers of cerebrovascular disease. Stroke 2015;46:3154-60 CrossRef Medline

7. De Cocker LJ, Compter A, Kappelle LJ, et al. Cerebellar cortical infarct cavities and vertebral disease. Neuroradiology 2016;58:853-57 CrossRef Medline

8. Caplan LR, Hennerici M. Impaired clearance of emboli (washout) is an important link between hypoperfusion, embolism and ischemic stroke. Arch Neurol 1998;55:1475-82 CrossRef Medline

(D) L.J.L. De Cocker Department of Radiology AZ Maria Middelares Ghent, Belgium 